\title{
A Case of Ultrasound Diagnosis of Intestinal Ascariasis Clinically Simulating Intussusception
}

\author{
Ibrahima Niang1* ${ }^{*}$, Axel Kayembe ${ }^{1}$, Cheikh Tidiane Diop², Mamadou Ly¹, Fallou Galass Niang ${ }^{3}$, \\ Abdourahmane Ndong4, Serigne Ahma Mbacké Dia ${ }^{2}$, Abdoulaye Dione Diop1, Sokhna Ba ${ }^{1}$
}

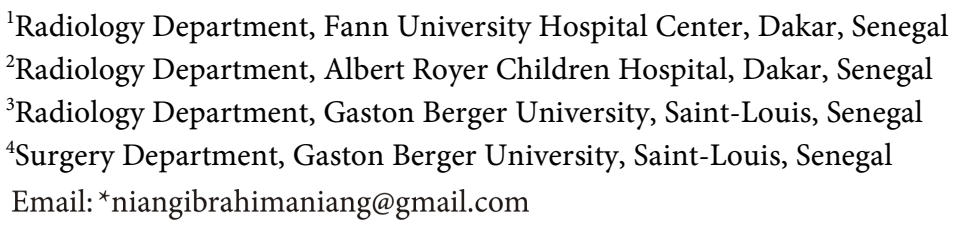

How to cite this paper: Niang, I., Kayembe, A., Diop, C.T., Ly, M., Niang, F.G., Ndong, A., Dia, S.A.M., Diop, A.D. and $\mathrm{Ba}, \mathrm{S}$. (2020) A Case of Ultrasound Diagnosis of Intestinal Ascariasis Clinically Simulating Intussusception. Open Access Library Journal, 7: e6840.

https://doi.org/10.4236/oalib.1106840

Received: September 19, 2020

Accepted: October 17, 2020

Published: October 20, 2020

Copyright $\odot 2020$ by author(s) and Open Access Library Inc.

This work is licensed under the Creative Commons Attribution International License (CC BY 4.0).

http://creativecommons.org/licenses/by/4.0/

\begin{abstract}
Ascaris lumbricoides is the most common helminth affecting humans. It is endemic in tropical and underdeveloped countries. It particularly infects children but most often is asymptomatic. Sometimes, it can mimic a surgical abdominal emergency. When it is suspected, its diagnosis is made on the parasitological examination of stool. We here report the case of a diagnosis of intestinal ascariasis made on ultrasound in an 8-year-old child who consulted for an acute abdominal syndrome which initially suggested an acute intussusception.
\end{abstract}

\section{Subject Areas}

Radiology \& Medical Imaging

\section{Keywords}

Ascaris lumbricoides, Pediatrics, Roundworm, Intussusception, Ultrasound

\section{Introduction}

Ascariasis is an infection caused by a giant roundworm named Ascaris lumbricoides, with about 760 million cases worldwide [1]. It is particularly prevalent in tropical and underdeveloped countries and most often infects malnourished children living in unsanitary conditions [2]. Most often asymptomatic, its diagnosis is made on the parasitological examination of stool when clinically suspected [3]. Acute intussusception is a common pediatric emergency. Its symptoms are resumed by the clinical triad of abdominal pain, vomiting, and bloody 
diarrhea. Ultrasound is the best imaging modality in the diagnosis [4]. We report a case of an intestinal ascariasis diagnosed by ultrasound in an 8-year-old child who consulted for an acute abdominal syndrome suggesting initially an acute intussusception.

\section{Case Report}

An 8-year-old male patient was brought in consultation for acute abdominal pain evolving for a week with recent exacerbation. It was associated with an episode of vomiting and bloody diarrhea. Clinical examination showed a general condition without fever or signs of dehydration. There was no tenderness or palpable mass. With the clinical triad (abdominal pain, vomiting, bloody diarrhea), the emergency physician suspected intussusception and requested an abdominal ultrasound.

The first part of the ultrasound examination performed with a low-frequency convex probe did not show any particularity of the intraabdominal solid organs as well as the bile and pancreatic tracts. There was no ascites or intra-abdominal lymphadenopathy. The second part of the exam was performed with a high-frequency linear probe. It visualized non-dilated small bowel containing in their lumen, formations with hyperechoic walls with hypoechoic center of tubular shape on the longitudinal sections realizing a rail appearance (Figure 1); and rounded shape, target on the axial sections (Figure 2). These formations were mobile during the exam with serpentine movements. There was no sign of intussusception or other abdominal abnormality. In total, the ultrasound concluded in the presence of multiple Ascaris lumbricoides in the small bowel without any sign of intussusception, bowel obstruction, or other complications. The patient was hospitalized for 24 hours and received medical treatment with
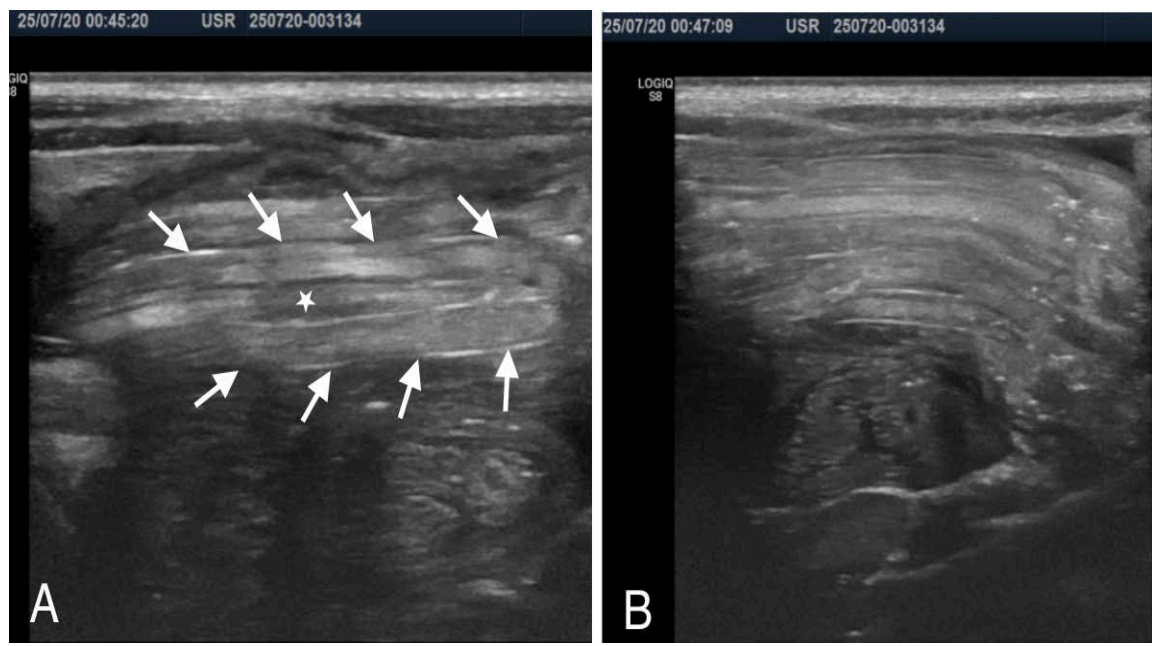

Figure 1. Abdominal ultrasound with the high-frequency probe, longitudinal view. (A) focus on an Ascaris lumbricoides in longitudinal section in the small bowel. Its wall is delimited by white arrows and its belly at the center (white star); (B) several Ascaris in longitudinal sections, entangled in the lumen of the small bowel, giving the appearance of "Spaghetti". 

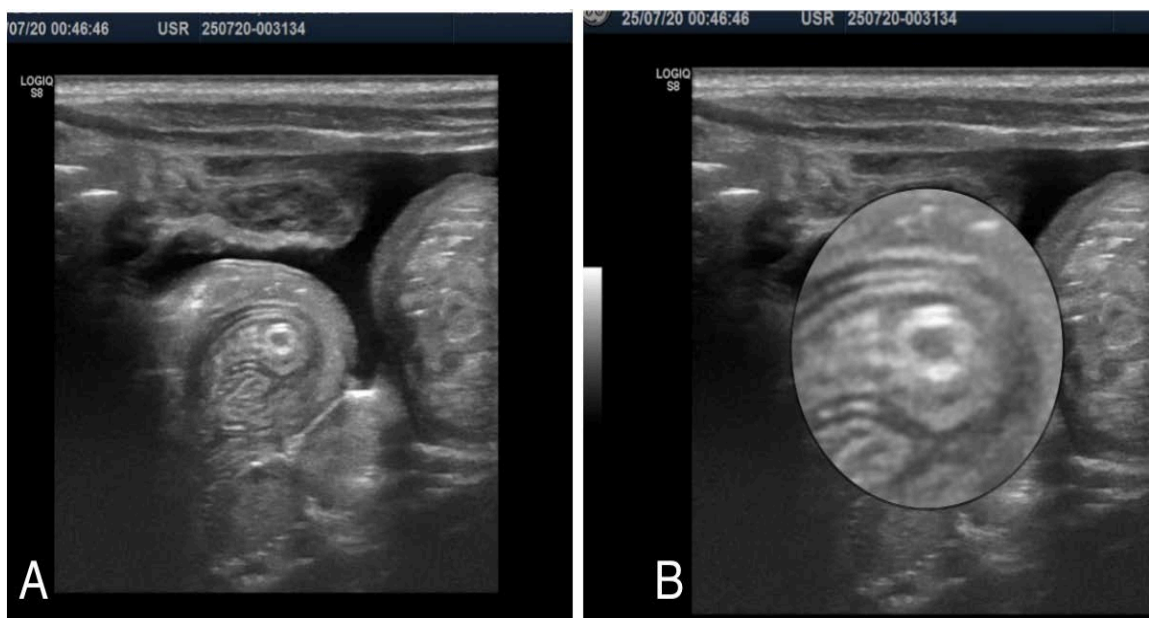

Figure 2. Abdominal ultrasound with the high-frequency probe, axial view. (A) Ascaris lumbricoides in axial section in the small bowel; (B) zoom on the axial section of the roundworm showing the target aspect.

Mebendazole $100 \mathrm{mg}$ twice a day for 3 days associated with symptomatic treatment. In the follow-up visit a week later, the clinical signs had improved and the parents just reported a worm emission during another episode of vomiting. Full recovery was confirmed two weeks later with a normal parasitological examination of the stool.

\section{Discussion}

Ascariasis is endemic in underdeveloped areas and particularly affects children [5]. Its clinical manifestations are polymorphic depending on the phase of infection. During the gastrointestinal phase, digestive signs are more frequent and may mimic an acute abdominal syndrome [6]. In our case, the patient's clinical presentation suggested an intussusception because the patient presented the clinical triad (abdominal pain, vomiting and bloody diarrhea). Despite its non-specificity, this triad very suggestive of this diagnosis in children [4]. Ultrasound is the key examination for the diagnosis of intussusception. In our patient, it has helped to rule out this diagnosis. As for ascariasis, its diagnosis is usually made based on a parasitological study of the stool [3]. But in this case, ultrasound performed with the high-frequency probe, made this diagnosis by recognizing its ultrasound aspects that have already been described since the 1980s [7]. However, it is important to note that the presence of ascariasis responsible for intussusception is also possible and has already been reported by several authors [8] [9]. Besides, it is important to know the differential diagnoses of Ascaris lumbricoides on ultrasound such as nasogastric tubes, surgical drain, and ventriculoperitoneal bypass [10]. Ultrasound could also be used in post-treatment follow-up to evaluate the presence and viability (mobility) of roundworms [11]. In endemic areas of ascariasis, radiologists and sonographers should know the ultrasound appearance of Ascaris lumbricoides. They should also, always look for its presence during abdominal ultrasounds, particularly in children who are 
more at risk, to avoid progression to complications. Since the development and of the performance of ultrasound machines, this diagnosis is made easier. In our case, ultrasound had a double interest by ruling out other causes of abdominal pain in children and possible complication of ascariasis. Ultrasound remains the best imaging modality for the diagnosis because it is rapid, non-invasive, available, and cost-effective.

\section{Conclusion}

In endemic settings, ultrasound plays a key role in the management of pediatric abdominal emergency. Ascariasis should be always considered as a possible diagnosis and ultrasound signs in favor should be looked for during exploration by the high-frequency probe.

\section{Conflicts of Interest}

The authors declare no conflicts of interest regarding the publication of this paper.

\section{References}

[1] Brooker, S.J. and Pullan, R.L. (2013) Ascaris lumbricoides and Ascariasis: Estimating Numbers Infected and Burden of Disease. In: Ascaris. The Neglected Parasite, Elsevier, Amsterdam, 343-362. https://doi.org/10.1016/B978-0-12-396978-1.00013-6

[2] Yetim, I., Ozkan, O.V., Semerci, E. and Abanoz, R. (2009) Rare Cause of Intestinal Obstruction, Ascaris lumbricoides Infestation: Two Case Reports. Cases Journal, 2 Article No. 7970. https://doi.org/10.4076/1757-1626-2-7970

[3] Wu, S. (2009) Sonographic Findings of Ascaris lumbricoides in the Gastrointestinal and Biliary Tracts. Ultrasound Quarterly, 25, 207-209.

https://doi.org/10.1097/RUQ.0b013e3181c47a2d

[4] Franchi, S., Martelli, H., Paye-Jaouen, A., Goldszmidt, D. and Pariente, D. (2005) Invagination intestinale aiguë du nourrisson et de l'enfant. EMC-Pédiatrie, 2, 45-57. https://doi.org/10.1016/j.emcped.2004.11.001

[5] Crompton, D.W.T. (2001) Ascaris and Ascariasis. Advances in Parasitology, 48, 285-375. https://doi.org/10.1016/S0065-308X(01)48008-0

[6] Schulze, S.M., Chokshi, R.J., Edavettal, M. and Tarasov, E. (2005) Acute Abdomen Secondary to Ascaris lumbricoides Infestation of the Small Bowel. The American Surgeon, 71, 505-507. https://doi.org/10.1177/000313480507100611

[7] Peck, R.J. (1990) Ultrasonography of Intestinal Ascaris. Journal of Clinical Ultrasound, 18, 741-743. https://doi.org/10.1002/jcu.1990.18.9.741

[8] Khalifa, A.B.H., Jebali, A., Kedher, M. and Trabelsi, A. (2013) Les étiologies infectieuses des invaginations intestinales aiguës idiopathiques chez l'enfant. Annales de Biologie Clinique, 71, 389-393. https://doi.org/10.1684/abc.2013.0859

[9] Karatepe, O., Tükenmez, M., Hünerli, K., Citlak, G., Salmaslıglu, A., Battal, M., et al. (2008) Ascaris as a Leading Point for Small-Bowel Intussusception in an Adult: A Rare Cause of Intussusception. The American Journal of Emergency Medicine, 26, 381.E3-381.E4. https://doi.org/10.1016/j.ajem.2007.05.022

[10] Mahmood, T., Mansoor, N., Quraishy, S., Ilyas, M. and Hussain, S. (2001) Ultrasonographic Appearance of Ascaris lumbricoides in the Small Bowel. Journal of UI- 
trasound in Medicine, 20, 269-274. https://doi.org/10.7863/jum.2001.20.3.269

[11] Montorfano, M. (1998) Ascaris lumbricoides. Role of Ultrasound in Diagnosis and Management of Abdominal Manifestation. JEMU Journal déchographie et de médecine ultra-sonore, 19, 394-398. 